\title{
STEAM-GAAR Field Learning Model to Enhance Grit
}

\author{
Wannaporn Chujitarom ${ }^{1} \&$ Pallop Piriyasurawong ${ }^{1}$ \\ ${ }^{1}$ King Mongkut's University of Technology North Bangkok, Thailand \\ Correspondence: Wannaporn Chujitarom, King Mongkut's University of Technology North Bangkok, Thailand. \\ Tel: 6-687-555-9392. E-mail: peterpan-digitalart@hotmail.com
}

Received: June 18, 2018

doi:10.5539/ies.v11n11p23
Accepted: July 24, $2018 \quad$ Online Published: October 22, 2018

URL: https://doi.org/10.5539/ies.v11n11p23

\begin{abstract}
The STEAM-GAAR Field Learning Model to Enhance Grit is a learning model using STEAM education (Science, Technology, Engineering, Art and Mathematics) integrated with gamification (G), animation (A), augmented reality (AR) and space utilization (Field) to promote the factors that enhance a learner's grit. The purpose of this research is to: (1) synthesize a STEAM-GAAR Field Learning Model to Enhance Grit; (2) evaluate the STEAM-GAAR Field Learning Model to Enhance Grit. The sample is made up of ten specialists-two instructional model design specialists, two STEAM education specialists, two gamification specialists, two animation specialists, and two augmented reality (AR) specialists-selected by purposive sampling. The instrument used in the study was an evaluation form with regard to the Model. The statistics used in the study were arithmetic mean and standard deviation. The results show that: (1) a STEAM-GAAR Field Learning Model to Enhance Grit contains four elements. The first element relates to input factors including 1) Expected Learning Outcomes (ELO), 2) Learning Objectives, 3) Teacher Analysis, 4) Student Analysis, 5) Content Analysis, 6) Environment Analysis, and 7) The Learning Management Plan. The second element relates to the STEAM-GAAR Field Learning Process, including 1) Investigate by Game, 2) Discover by AR-Game, 3) Connect by Animation and Game, 4) Create by Game Animation and AR and 5) Reflect by Knowledge Exchange Field. The third element relates to evaluating learning achievement and grit, conducted via teachers' observation and an evaluation form. And the final element relates to an analysis of feedback; (2) All ten specialists agreed that the STEAM-GAAR Field Learning Model to Enhance Grit developed through this study demonstrates the highest level of appropriateness $(\overline{\mathrm{x}}=4.65$, S.D. $=$ $0.57)$.
\end{abstract}

Keywords: instructional model, STEAM education, gamification, animation, augmented reality

\section{Introduction}

"May all readers be blessed with pure perseverance, sharp wisdom and complete physical health" (His Majesty King Bhumibol Adulyadej, 1996, p. 7) from the preface to the story of Mahajanaka.

His Majesty King Bhumibol Adulyadej completed the translation of the story of Mahajanaka in 1988 and was graciously pleased to publish it on the occasion of his Golden Jubilee to be considered for the benefit of the lives of the people (His Majesty King Bhumibol Adulyadej, 1996, pp. 6-7). The story of Mahajanaka is a royal work of His Majesty. It is a piece of Buddhist literature which shows that the most important people should have grit. (Suwanapichon, 1996, pp. 2-3). Grit is an important feature that is found in male success in life. Research indicates that some people are more persistent than others and will be able to achieve more goals than others. Both internal factors and external factors enhance grit. There are 4 internal factors: interest, practice, purpose and hope (Duckworth, 2016). Grit is also one of the most important features of 21st Century learners (Tomorrowtodayglobal, 2016). Nowadays, education must change. Students must develop 21st Century skills in order to live. Modern learning must focus on applying knowledge and not just learning the contents (Panich, 2013).

\subsection{STEAM Education}

STEAM education was developed on the basis of STEM education, the application of knowledge in science (S), technology (T), engineering (E) and mathematics (M). By integrating art (A) into STEM education it then becomes STEAM education. The aim is to ensure that they have important skills in order to live in the 21 st Century (Yakman, 2008). The inclusion of art in STEAM education will allow students to use systematic thinking skills and develop creativity, and will also enhance student motivation (Bazler \& Sickle, 2017). STEAM education also 
encourages learners to learn how to investigate, solve problems, work together and think critically (Edudemic, 2017; Educationcloset, 2017; Edutopia, 2017; Stemtosteam, 2017). The STEAM education process includes 5 steps: (1) Investigate (2) Discover (3) Connect (4) Create and (5) Reflect. Learners can reflect on learning, by a rubrics assessment or student's portfolio (Educationcloset, 2017).

\subsection{Gamification}

Gamification is the introduction of the style or the thinking behind a game. It can be applied to non-game content. The aim is to encourage people to participate in learning, to inspire and promote learning, to solve problems, or to drive behavior. IS THIS WHAT YOU MEAN? The purpose is to help them ask questions. It helps them choose a topic from a variety of problems and to be consistent with regard to the answers you want to receive (Karl, 2012; Brian 2014; Naomi \& Irit 2015; Emerging trends Introduction to Gamification, 2014, p. 6). Nowadays, games are becoming more and more popular in the educational field. The game's application structure is applied to non-game situations and is not designed for entertainment. In the field of education, it is possible to give rewards for answering questions, or reward the students when s/he is able to do the task assigned. It is popular because it can be displayed to the learner through a website or through social media (Miller, 2014).

\subsection{Animation}

Animation is a term derived from the Latin word "Animare" meaning "to live" (Lieser, 2010). Animation means that images are taken in consecutive sequence and then the image is changed until the phenomenon is called a persistant image, resulting in a continuous animation (Laowansiri, 1989). The advantages of animation to the study are: (1) it can convey the story in a way that a person cannot or that is difficult to explain (2) it can explain a complex story in such a way at to make it easier to understand (Laowansiri, 1989). There are many types of animation, for example two-dimensional animation (2D), three-dimensional animation (3D) and stop motion animation, each of which can be selected as appropriate (Toongoggles, 2018; Bloopanimation, 2018). The most popular cartoon animation in the 1980s and the 1990s are 2D animation, such as the Disney classics, The Flinstones, and Looney Tunes (Toongoggles, 2018).

\subsection{Augmented Reality (AR)}

Augmented Reality (AR) is the technology that was originally developed from Virtual Reality (VR) being applied to the real world. AR interacts with the real world through the camera system, then displays an image on a monitor, computer monitor or display device. AR can display many features such as image files, videos, animations with sound or 3D objects, etc. AR is developed using computer software and occurs in real time (Furht, 2011; Miller, 2014; Srifa, 2016; Meesuwan, 2011; Tansiri, 2010). AR consists of 3 processes: (1) Image Analysis. This begins with the establishment of a database of images or monographs by converting image data captured from a video camera into a binary image. (2) Pose Estimation. This step involves computing the 3D metric to determine the relationship between the captured cameras coordinates and the coordinates of the Marker contained in the database. The user analyzes the values obtained with the data stored on the computer. (3) 3D Rendering process. This involves adding 3D rendering and displaying it on the assigned Pose Estimation (Meesuwan, 2011). AR also is one of the Gartner Top 10 Strategic Technology Trends for 2018, in the form of Immersive Experience, which is changing the way that people perceive and interact with the digital world (Panetta, 2017).

\subsection{Field}

Field, refer to virtual environment resulting from the processing of computer programs, and can be used through the network. It operates through the use of information equipment, just like social Media, online games and applications for communication (Bartle, 2004; Bainbridge, 2007; Rattanawijarn \& Pongsanit, 2016).

Researchers have recognized the importance of developing learning models to enhance the development of grit through the STEAM learning process, which allows students to learn all about science, technology, engineering, art and math. This is aided by applying information technology such as gamification (G), animation (A) and augmented reality (AR). Through this, the real world field is brought into the classroom, while the virtual world field is outside the classroom (Field). It is used to reinforce four internal factors that will lead to the development of grit on the part of the learner: interest, practice, purpose and hope. It will help to synthesize and evaluate the appropriateness of the STEAM-GAAR Field Learning Model to Enhance Grit.

\section{Method}

This research method consists of setting objectives, conduct the research process and synthesize the conceptual framework of the model. 


\subsection{Objective}

1) Synthesize a STEAM-GAAR Field Learning Model to Enhance Grit.

2) Evaluate the STEAM-GAAR Field Learning Model to Enhance Grit.

\subsection{Research Process}

The process of creating a STEAM-GAAR Field Learning Model to Enhance Grit is divided into 11 steps as follows:

1) Literary review of relevant data and theories which includes: Grit (Adulyadej, 1999; Duckworth, 2016) STEAM education (Yakman, 2008; Edudemic, 2017; Educationcloset, 2017), Gamification (KAPP, 2012; Burk, 2014), Animation (Lieser, 2010; Laowansiri, 1989) and Augmented Reality (Furht, 2011; Srifa, 2013; Meesuwan, 2014). This involves analyzing 30 relevant international research articles. These indicate that technology incorporating gamification, animation and AR can promote 4 internal factors with regard to grit: interest, practice, purpose and hope.

2) Synthesize the conceptual framework of the STEAM-GAAR Field Learning Model to Enhance Grit.

3) Analyze and synthesize the factors that promote grit.

4) Synthesize the research articles in the form of a table that relates findings to gamification, animation and AR in the promotion of internal grit factors including interest, practice, purpose and hope.

5) Visualize the link between gamification, animation, AR and the internal factors of grit in the form of interest, practice, purpose and hope.

6) Synthesize a STEAM-GAAR Field Learning Model to Enhance Grit.

7) Develop a STEAM-GAAR Field Learning Model to Enhance Grit, focused on STEAM education, gamification, animation, AR, real world and virtual world field to enhance the internal grit factors.

8) Submit the STEAM-GAAR Field Learning Model to Enhance Grit to an advisor for further advice.

9) Create a tool for evaluating the suitability of the learning model, using the Likert scale as a model assessment form. The format of five-level Likert items is Strongly Disagree, Disagree, Neither Agree nor Disagree, Agree, Strongly Agree. Establish the interpretation criteria as follows in terms of suitability: 1.00-1.80 mean lowest, 1.81-2.60 mean low, 2.61-3.40 mean medium, 3.41-4.20 mean high and 4.21-5.00 mean highest.

10) Propose the model assessment form to ten specialists employed as university lecturers, selected by purposive sampling. Two instructional model design specialists are associate professors and university lecturers in the faculty of Information and Communication Technology for Education; two STEAM education specialists are university instructors and researchers in the field of STEAM education; two gamification specialists also work as a university instructors and researchers in the gamification field; two animation specialist are a famous animation director and an assistant professor at the university; two augmented reality (AR) specialists are a researcher in the AR field and an assistant professor at the university. All ten specialists have experience in their field for at least five years. The suitability of the model is evaluated using a five-point Likert scale.

11) Analyse the results in terms of the suitability of the learning model by using the mean $(\overline{\mathrm{x}})$ and standard deviation (S.D.) measures then arrive at a conclusion.

\subsection{Framework}

1) The independent variable is the STEAM-GAAR Field Learning Model to Enhance Grit.

2) The dependent variables are grit and learning achievement. (Figure 1) 


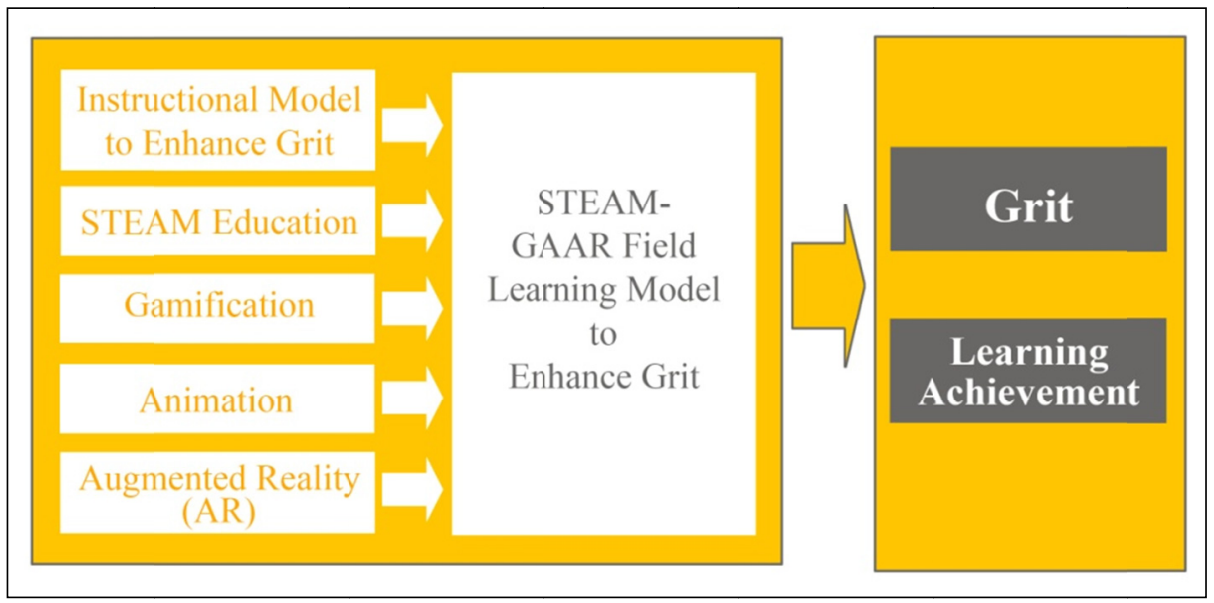

Figure 1. Framework

\section{Results}

\subsection{The Researcher Synthesized STEAM-GAAR Field Learning Model to Enhance Grit into 4 parts.}

The STEAM-GAAR Field Learning Model to Enhance Grit was suitable for using gamification, animation and AR integrated with the STEAM education process to stimulate factors that promote grit, including purpose, interest, hope and practice (Adulyadej, 1999; Duckworth, 2016). (Figure 2)

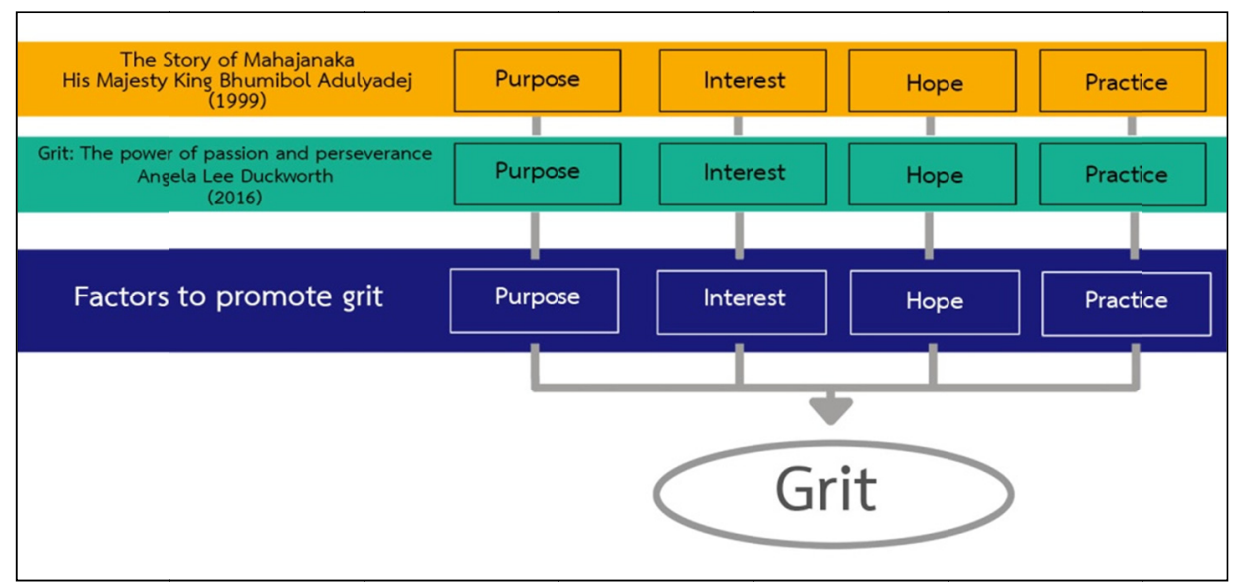

Figure 2. Factors to promote grit

According to a study of 30 international research papers, it would appear that gamification, animation and augmented reality (AR) technology can promote four factors in the form of purpose, interest, hope and training (Adulyadej, 1999; Duckworth, 2016). Gamification can promote the creation of objectives for learners. In addition, learners are interested in practicing in order to achieve the purpose. Animation can motivate learners to a greater extent than traditional approaches. In addition, augmented reality (AR) is able to generate more interest and participation on the part of learners. The table containing a synthesis of research article findings will show the relationship of gamification, animation and AR to the promotion of the internal grit factors (Table 1). 
Table 1. Synthesis of research articles related to gamification, animation and AR in terms of promoting internal grit factors (Purpose, Interest, Hope and Practice)

\begin{tabular}{|c|c|}
\hline & Research Article \\
\hline 1. & $\begin{array}{l}\text { Antonaci, A., Klemke, R., Stracke, C. M., \& Specht, M. (2017, April). Gamification in MOOCs to enhance } \\
\text { users' goal achievement. In Global Engineering Education Conference (EDUCON), } 2017 \text { IEEE (pp. } \\
\text { 1654-1662). IEEE. }\end{array}$ \\
\hline 2. & $\begin{array}{l}\text { Landers, R. N., Bauer, K. N., \& Callan, R. C. (2017). Gamification of task performance with leaderboards: A } \\
\text { goal setting experiment. Computers in Human Behavior, 71, 508-515. }\end{array}$ \\
\hline
\end{tabular}

3. Hamari, J. (2017). Do badges increase user activity? A field experiment on the effects of gamification. Computers in human behavior, 71, 469-478.

4. Barata, G., Gama, S., Jorge, J., \& Gonçalves, D. (2013, July). So fun it hurts-gamifying an engineering course In International Conference on Augmented Cognition (pp. 639-648). Springer, Berlin, Heidelberg. Tan, K. L., \& Lim, C. K. (2017, October). Digital heritage gamification: An augmented-virtual walkthrough to

5. learn and explore historical places. In AIP Conference Proceedings (Vol. 1891, No. 1, p. 020139). AIP Publishing.

Baker, E. J., Bakar, J. A. A., \& Zulkifli, A. N. (2017, October). Elements of museum mobile augmented reality

6. for engaging hearing impaired visitors. In AIP Conference Proceedings (Vol. 1891, No. 1, p. 020033). AIP Publishing.

7. McMillan, K., Flood, K., \& Glaeser, R. (2017). Virtual reality, augmented reality, mixed reality, and the marine conservation movement. Aquatic Conservation: Marine and Freshwater Ecosystems, 27(S1), 162-168.

Bazarov, S. E., Kholodilin, I. Y., Nesterov, A. S., \& Sokhina, A. V. (2017, October). Applying Augmented

8. Reality in practical classes for engineering students. In IOP Conference Series: Earth and Environmental Science (Vol. 87, No. 3, p. 032004). IOP Publishing.

Safitri, R., Yusra, D. S., Hermawan, D., Ripmiatin, E., \& Pradani, W. (2017, August). Mobile tourism

9. application using augmented reality. In Cyber and IT Service Management (CITSM), 2017 5th International Conference on (pp. 1-6). IEEE.

Kiat, L. B., Ali, M. B., Halim, N. D. A., \& Ibrahim, H. B. (2016, October). Augmented Reality, Virtual

10. Learning Environment and Mobile Learning in education: A comparison. In e-Learning, e-Management and e-Services (IC3e), 2016 IEEE Conference on (pp. 23-28). IEEE.

11. Chang, R. C., \& Yu, Z. S. (2017, May). Application of Augmented Reality technology to promote interactive learning. In Applied System Innovation (ICASI), 2017 International Conference on (pp. 1673-1674). IEEE.

Stuchlíková, L., Kósa, A., Jakuš, J., Sušoliak, M., Donoval, D., \& Hrbácek, J. (2014, May). Interactive

12. animation as a motivation tool. In Microelectronics Education (EWME), 10th European Workshop on (pp. 116-119). IEEE.

Mastang, A. N., Bais, B., Husain, H., Kamal, N., Hanafi, M., Arsad, N., ... \& Abdullah, O. R. A. (2013, October). Impact of Fiber to the Home (FTTH) animation on student learning and motivation in electrical

13. engineering. In Information Technology Based Higher Education and Training (ITHET), 2013 International Conference on (pp. 1-5). IEEE.

Pérez-López, D., Contero, M., \& Alcaniz, M. (2010, July). Collaborative development of an augmented reality

14. application for digestive and circulatory systems teaching. In Advanced Learning Technologies (ICALT), 2010 IEEE 10th International Conference on (pp. 173-175). IEEE.

Chen, M. P., \& Liao, B. C. (2015, July). Augmented reality laboratory for high school electrochemistry course.

15. In Advanced Learning Technologies (ICALT), 2015 IEEE 15th International Conference on (pp. 132-136). IEEE.

16. Banfield, J., \& Wilkerson, B. (2014). Increasing student intrinsic motivation and self-efficacy through gamification pedagogy. Contemporary Issues in Education Research (Online), 7(4), 291.

WANGPIPATWONG, T., \& CHITTRAKARN, P. (2009). The Design of Active Learning Environment with

17. the Integration of $3 \mathrm{D}$ animation. In Proceedings of the 17 th International Conference on Computers in Education, Hong Kong: Asia-Pacific Society for Computers in Education.

Khogali, S. E. O., Davies, D. A., Donnan, P. T., Gray, A., Harden, R. M., McDonald, J. Pippard, M.J. Pringle

18. S.D. \& Yu, N. (2011). Integration of e-learning resources into a medical school curriculum. Medical teacher, 33(4), 311-318.

Kato, Y., Chandrasiri, N. P., \& Suzuki, M. (2016, November). An application for encouraging positive

19. emotions by displaying an animation. In Control System, Computing and Engineering (ICCSCE), 2016 6th IEEE International Conference on (pp. 67-72). IEEE.
Summary

Gamification can

promote purpose and interest.

Gamification can promote purpose.

Gamification can

promote purpose and interest.

Gamification can promote purpose.

Gamification and AR can promote interest.

AR can promote interest.

AR can promote interest.

AR can promote interest.

AR can promote interest.

AR can promote interest.

AR can promote interest.

Animation can promote hope.

\section{Animation} can promote hope.

AR can promote hope.

AR can promote hope.

Gamification can promote hope.

Animation can promote hope.

Animation can promote hope.

Animation can promote hope. 
20. Birch, H. (2013). Motivational Effects of Gamification of Piano Instruction and Practice (Doctoral dissertation, University of Toronto (Canada)).

Yamabe, T., Asuma, H., Kiyono, S., \& Nakajima, T. (2011, August). Feedback design in augmented musical

21. instruments: A case study with a drum kit. In Embedded and Real-Time Computing Systems and Applications (RTCSA), 2011 IEEE 17th International Conference on (Vol. 2, pp. 126-129). IEEE.

Fernandez, C. A. T., Paliyawan, P., Yin, C. C., \& Thawonmas, R. (2016, October). Piano learning application

22. with feedback provided by an AR virtual character. In Consumer Electronics, 2016 IEEE 5th Global Conference on (pp. 1-2). IEEE.

23. Salman, F. H., \& Riley, D. R. (2016, December). Augmented reality crossover gamified design for sustainable engineering education. In Future Technologies Conference (FTC) (pp. 1353-1356). IEEE.

Kumar, H., \& Raghavendran, S. (2015). Gamification, the finer art: fostering creativity and employee engagement. Journal of Business Strategy, 36(6), 3-12.

Sotirakou, C., Papavasiliou, S., Mourlas, C., \& Van Isacker, K. (2015, October). Gamified mobile/online

25. learning for personal care givers for people with disabilities and older people. In Interactive Technologies and Games (iTAG), 2015 International Conference on (pp. 22-27). IEEE.

26. Pirker, J., Gutl, C., \& Astatke, Y. (2015, June). Enhancing online and mobile experimentations using gamification strategies. In Experiment@ International Conference (exp. at'15), 2015 3rd (pp. 224-229). IEEE. Silva, F., Analide, C., Rosa, L., Felgueiras, G., \& Pimenta, C. (2013). Gramification, Social Networks and Sustainable Environments. IJIMAI, 2(4), 52-59.

Barata, G., Gama, S., Jorge, J., \& Gonçalves, D. (2013, September). Engaging engineering students with

28. gamification. In Games and Virtual Worlds for Serious Applications (VS-GAMES), 2013 5th International Conference on (pp. 1-8). IEEE.

29. Barratt, P. (2017). Healthy competition: A qualitative study investigating persuasive technologies and the gamification of cycling. Health \& place, 46, 328-336.

Chujitarom, W., \& Piriyasurawong, P. (2017). Animation Augmented Reality Book Model (AAR Book

30. Model) to Enhance Teamwork. International Education Studies, 10(7), 59.

Gamification can

promote practice.

AR can promote practice.

AR can promote practice.

Gamification and AR can promote practice.

Gamification can

promote interest

and practice.

Gamification can promote practice.

Gamification can

promote practice.

Gamification can

promote practice.

Gamification can

promote interest and practice.

Gamification can promote practice.

Animation and AR can promote practice.

According to the international research articles from Table 1, it can be concluded that the four internal grit factors are linked to GAAR as follows: Purposes can be created using gamification (Research Articles 1-4); Interest can be created using gamification, animation and AR (Research Articles 5-11); Hopes can be created using animation (Research Articles 12-19); and Practice can also be created using gamification, animation and AR (Research Articles 20-30).

Based on the above analysis of the research documents, we can create link factors as shown in Figure 3.

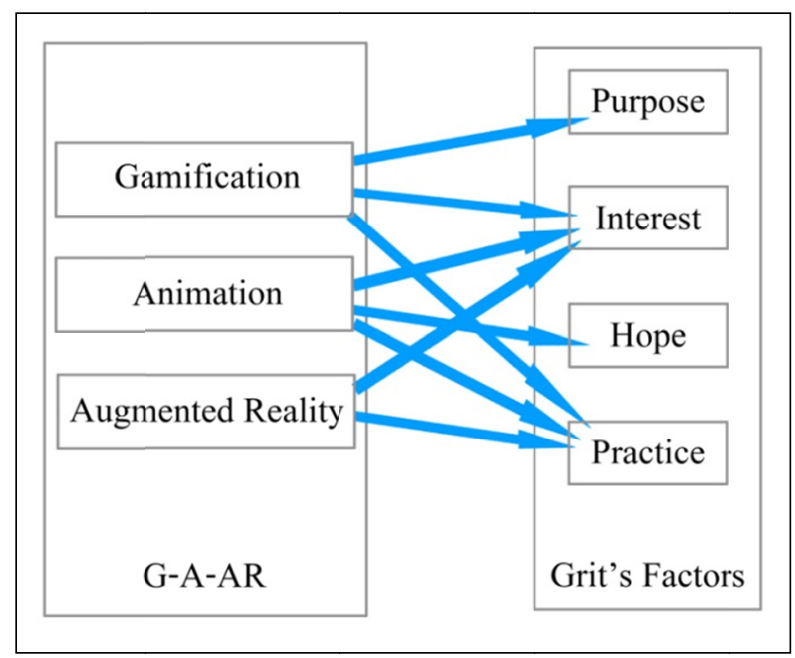

Figure 3. Linking gamification animation and augmented reality with grit's factor by analyzing research documents

Thus, the STEAM-GAAR Field Learning Model to Enhance Grit can be designed by dividing it into 4 elements as 
follows:

I) Element 1: Input Factors

1) The Expected Learning Outcome (ELO) is Grit.

2) The learning objective is to determine what the learner will learn.

3) Teacher Analysis involves teachers who are knowledgeable in terms of gamification, animation, and AR and teachers who can easily adapt to the content of the lesson.

4) Student Analysis involves considering the appropriateness of the student to the teaching style, such as the extent of the student's digital literacy. Age analysis will consider the student's ability to use learning equipment.

5) Content analysis is considered appropriate to a consideration of gamification, animation and AR.

6) Environment Analysis is an additional consideration. The school or real world field has to have internet access with sufficient speed. In addition, there must be tablets or mobile devices that are suitable for use in AR in that they are suitable for use in the real world and in the virtual world.

7) The Learning Management Plan is to prepare the teaching process using gamification, animation, and AR that follows the STEAM-GAAER Field steps. The approach used needs to be appropriate to the content of the lesson.

\section{II) Element 2: The STEAM-GAAR Field Learning Processes}

1) Investigate by Game. This involves setting up a problem-solving question to achieve the learning objectives. The use of gamification as a facilitator facilitates learners' participation. It will be necessary to create a scoreboard for those who have problems, and ask good questions. It will incorporate the use of science to hypothesize and explore.

2) Discover by AR-Game. Students discover together, AR is combined with gamification to enhance the student's interest and engagement. This might include providing an AR Poster Puzzles experience around the venue. The students have to explore and find the correct answer to puzzles through the use of AR. The student might be asked to connect multiple images and collect as many points on the score board by using their knowledge of technology.

3) Connect by Animation and Game. When discovering a solution we combine knowledge with gamification, animation and AR to provide knowledge and interesting content. Games can link knowledge between learners. In addition, the animation can link the knowledge from the media to that of the learner. The student can then plan his/her work or creative plan using mathematical knowledge to calculate time, volume, budgets, etc.

4) Create by Game Animation and AR. This works according to a plan laid out by the application. Animation and AR can be used to inspire interest and games can be used to make learning fun and engaging. It can bring success and provide a complete assessment of each topic, such as the beauty of art and creativity. It can be used to manage complex workflows with regard to engineering.

5) Reflect by Knowledge Exchange Field. This is the use of field space in the real world, the place of study and the virtual world. This involves aspects of the internet network that are convenient today, such as social media. This can be used to exchange knowledge, ideas, questions and answers with instructors, learners, and external audiences in such a way as to reflect the student's performance and achievement. Learners can learn from mistakes and develop their work. It is a field space for speeches and for the encouragement of students who have the good intentions to be inspired to work in the future.

III) Element 3: The Learning Outcomes are grit and learning achievement. For this the teacher monitors progress by using formative assessment and summative assessment to compare learning outcomes, and to find the correlation between grit and the learning achievement

IV) Element 4: Analyzing feedback. This involves obtaining feedback from the students in order to analyze and improve the defects of the model (Figure 4). 


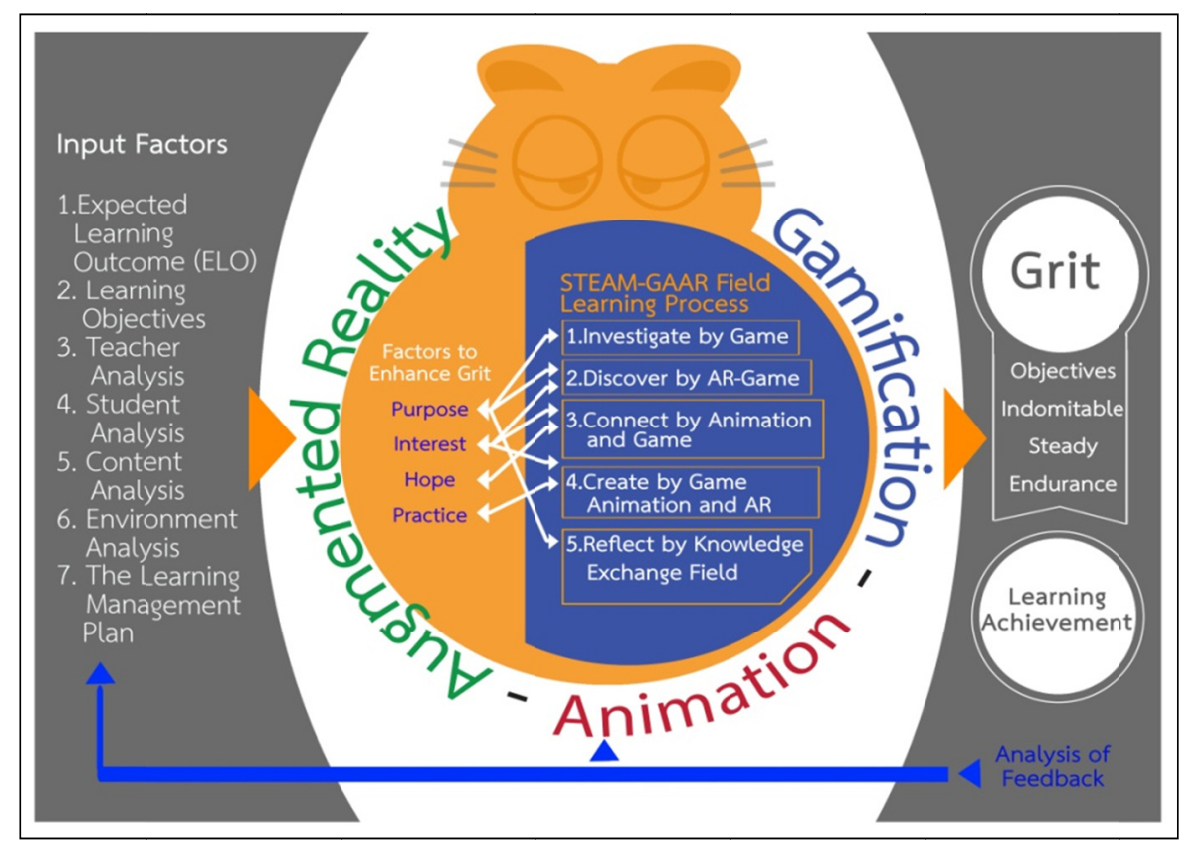

Figure 4. STEAM-GAAR field learning model to enhance grit

\subsection{The Assessment Results of the STEAM-GAAR Field Learning Model to Enhance Grit}

The Assessment Results of the STEAM-GAAR Field Learning Model to Enhance Grit are shown in Table 2

Criteria Suitability are: 1.00-1.80 mean lowest, 1.81-2.60 mean low, 2.61-3.40 mean medium, 3.41-4.20 mean high and 4.21- 5.00 mean highest.

Table 2. Arithmetic mean and standard deviation results from 10 specialists

\begin{tabular}{|c|c|c|c|c|}
\hline Elements & & $\begin{array}{l}\text { Evaluation } \\
\quad(\overline{\mathrm{x}}) \\
\end{array}$ & $\begin{array}{l}\text { Standard Deviation } \\
\text { (S.D.) }\end{array}$ & $\begin{array}{l}\text { Level of } \\
\text { Suitability }\end{array}$ \\
\hline \multirow{8}{*}{ Element 1: Input Factors } & $\begin{array}{l}\text { 1) Expected Learning Outcome (ELO) } \\
\text { is Grit. }\end{array}$ & 4.6 & 0.69 & Highest \\
\hline & 2) The learning objective & 4.8 & 0.42 & Highest \\
\hline & 3) Teacher Analysis & 4.8 & 0.42 & Highest \\
\hline & 4) Student Analysis & 5 & 0 & Highest \\
\hline & 5) Content analysis & 4.9 & 0.31 & Highest \\
\hline & 6) Environment Analysis & 4.8 & 0.42 & Highest \\
\hline & 7) The Learning Management Plan & 4.8 & 0.42 & Highest \\
\hline & Sum of Element 1 & 4.81 & 0.38 & Highest \\
\hline \multirow{6}{*}{$\begin{array}{l}\text { Element 2: STEAM-GAAR Field Learning } \\
\text { Process }\end{array}$} & 1) Investigate by Game & 4.6 & 0.51 & Highest \\
\hline & 2) Discover by AR-Game & 4.6 & 0.51 & Highest \\
\hline & 3) Connect by Animation and Game & 4.6 & 0.51 & Highest \\
\hline & 4) Create by Game Animation and AR & 4.7 & 0.48 & Highest \\
\hline & $\begin{array}{l}\text { 5) Reflect by Knowledge Exchange } \\
\text { Field }\end{array}$ & 4.8 & 0.42 & Highest \\
\hline & Sum of Element 2 & 4.66 & 0.49 & Highest \\
\hline \multirow{3}{*}{ Element 3: Learning Outcome } & 1) Grit & 4.7 & 0.48 & Highest \\
\hline & 2) Learning Achievement & 4.8 & 0.42 & Highest \\
\hline & Sum of Element 3 & 4.75 & 0.45 & Highest \\
\hline \multirow{2}{*}{ Element 4: Analyzing of feedback } & Analyzing of feedback & 4.4 & 0.96 & Highest \\
\hline & Sum of Element 4 & 4.4 & 0.96 & Highest \\
\hline Results & & 4.65 & 0.57 & Highest \\
\hline
\end{tabular}


The STEAM-GAAR Field Learning Model to Enhance Grit was rated at the highest level $(\bar{x}=4.65$, S.D. $=0.57)$ of suitability by ten specialists. Element 1 was evaluated at 4.81 with a standard deviation of 0.38 . Element 2 was evaluated at 4.66 with a standard deviation of 0.49. Element 3 was evaluated at 4.75 with a standard deviation of 0.45 . Element 4 was evaluated at 4.40 with a standard deviation of 0.96 . These results indicate that each element was deemed to be at the highest appropriate level.

\section{Discussion}

The STEAM-GAAR Field Learning Model to Enhance Grit that applies gamification, animation and augmented reality to the STEAM education process, and to action in the real world and virtual field, can be used to enhance grit, with all ten specialists agreeing that the developed instructional model was at the highest appropriate level. Results relate to those of Techakosit and Nilsook (2016) that AR enhances STEM literacy by using the Learning Process of Scientific Imagineering in their 'The Learning Process of Scientific Imagineering through AR in Order to Enhance STEM Literacy' research. The results are also consistent with those of Nuttakan Pakprod and Panita Wannapiroon (2014) in the research article 'Development of Interactive Instructional Model Using Augmented Reality based on Edutainment to Enhance Emotional Quotient' which suggest that a model using AR and Edutainment is highly suitable for emotional quotient development, including setting goals and objectives. They also relate to Wannaporn Chujitarom and Namon Jeerungsuwan's (2017) 'A Model of an Augmented Reality Book Using Animation for Sustainable Learning based on the AAA Model' using AR and animation for a sustainable learning outcome including Analysis, Activity and Autentic Assessment. They also relate to 'Designing Spaces for Creativity and Divergent Thinking: Pre-Service Teachers Creating Stop Motion Animation on Tablets (O'Byrne, Radakovic, Hunter-Doniger, Fox, Kern \& Parnell, 2018), and to the findings of Angela L. Duckworth, Christopher Peterson, Michael D. Matthews and Dennis R. Kelly in 'Grit: Perseverance and Passion for Long-Term Goals' shown that high achievers included a strong interest, sustained and focused in the particular field' (2007).

\section{Conclusions}

The STEAM-GAAR Field Learning Model to Enhance Grit has a highest level of appropriateness $(\overline{\mathrm{x}}=4.65$, S.D. $=$ 0.57 ) according the assessment of ten specialists. The model can be separated into 4 elements. The first element contains the following input factors: 1) Expected Learning Outcomes (ELO), 2) Learning Objectives, 3) Teacher Analysis, 4) Student Analysis, 5) Content Analysis, 6) Environment Analysis, and 7) The Learning Management Plan. The second element, the STEAM-GAAR Field Learning Process, includes: 1) Investigate by Game, 2) Discover by AR-Game, 3) Connect by Animation and Game, 4) Create by Game Animation and AR and 5) Reflect by Knowledge Exchange Field. The third element, evaluating learning achievement and grit, was conducted via teachers' observations and an evaluation form. The last element is the analysis of feedback. The model focuses on motivating students to learn through gamification, animation, AR and encourages the development of grit as part of the STEAM education process. The STEAM-GAAR Field Learning Model can enhance the internal grit factors in the form of purpose, interest, hope and practice. The advantage of the use of gamification is to make people interested in setting purpose and becoming involved in practice. The benefit of animation is that it encourages learners to understand the content of the lessons, and have more hope in terms of learning achievement. In addition, AR can encourage the learner to participate more and be more interested. The STEAM education process approach to learning works across subjects, engages students through experimentation and encourages the development of grit. The real world field and the virtual world field can promote learning anywhere and anytime, and is suitable for the needs of 21 st Century students. In terms of future work, the STEAM-GAAR Field Learning Model to Enhance Grit can be applied to all majors, depending on the content and the age of the learner. This learning model will allow learners to become interested in the content of the lesson and have more grit, which is an important aspect of every student's life.

\section{Acknowledgments}

The researcher would like to thanks Assoc. Prof. Dr. Pallop Piriyasurawong, Assoc. Prof. Dr. Namon Jeerungsuwan, Assoc. Prof. Dr. Prachyanun Nilsook, Assoc. Prof. Dr. Panita Wannapiroon, Asst. Prof. Dr. Somsak Techakosit, Asst. Prof. Chaiporn Panichrutiwong, Asst. Prof. Dr. Aviruth Charoensup, Asst. Prof. Dr. Walaiporn Nakapan, Dr. Kongkiat Hirankerd, Dr. Sudarat Srima, and Dr. Torsangrasmee Teetakaew, who have given all useful advices. This research was partially supported by the Graduate Thesis Research Grant (GTRG) from the Graduate College, King Mongkut's University of Technology North Bangkok.

\section{References}

Adulyadej, B. (1996). The Story of Mahajanaka. Bangkok: Amarin Printing \& Publishing Public Company Limited. 
Bainbridge, W. S. (2007). The Scientific Research Potential of Virtual Worlds. Science, 5837(317), 472-476. https://doi.org/10.1126/science.1146930

Bartle, R. A. (2004). Designing virtual worlds. New Riders.

Bazler, J., \& Sickle, M. V. (2017). Cases on STEAM Education in Practice. IGI global. https://doi.org/10.4018/978-1-5225-2334-5

Bloop Animation. (2018). The 5 Types of Animation. Retrieved from https://www.bloopanimation.com/types-of-animation/

Burke, B. (2014). Gamify: How gamification motivates people to do extraordinary things (p. 4). Brookline: Gartner, Inc.

Chujitarom, W., \& Jeerungsuwan, N. (2017). A Model of an Augmented Reality Book Using Animation for Sustainable Learning based on the AAA Model. RSU International Research Conference 2017. Pathumthanee. http://dx.doi.org/10.14458/RSU.res.2017.31

Duckworth, A. L. (2016). Grit: The power of passion and perseverance. Simon and Schuster.

Duckworth, A. L., Peterson, C., Matthews, M. D., \& Kelly, D. R. (2007). Grit: Perseverance and Passion for Long-Term Goals. Journal of Personality and Social Psychology, 92(6), 1087-1101. https://doi.org/10.1037/0022-3514.92.6.1087

Education Closet. (2017). WHAT IS STEAM?. Retrieved from https://educationcloset.com/steam/what-is-steam/

Edudemic Connecting Education \& Technology. (2017). STEM vs. STEAM: Why the "A" Makes a Difference. Retrieved from http://www.edudemic.com/stem-vs-steam-why-the-a-makes-all-the-difference/

Edutopia. (2017). STEM to STEAM: Art in K-12 is Key to Building a Strong Economy. Retrieved from https://www.edutopia.org/blog/stem-to-steam-strengthens-economy-john-maeda

Furht, B. (2011). Handbook of Augmented Reality. Florida: Springer. https://doi.org/10.1007/978-1-4614-0064-6

Kapp, K. M., Blair, L., \& Mesch, R. (2014). The gamification of learning and instruction Fieldbook. San Francisco: Wiley.

Laowansiri, P. (1989). Advanced Film Production. SukhothaiThammathirat Open University Publishing.

Lieser, W. (2010). The World of Digital Art. Potsdam: h.f.ullman publishing.

Meesuwan, W. (2011). AUGMENTED REALITY TECHNOLOGY FOR LEARNING. Journal of Education Naresuan University, 13(2), 119-128.

Miller. C. H. (2014). Digital Storytelling a creator's guide to Interactive Entertainment. Burington: Focal Press.

O’Byrne, I., Radakovic, N., Hunter-Doniger, T., Fox, M., Kern, R., \& Parnell, S. (2018). Designing Spaces for Creativity and Divergent Thinking: Pre-Service Teachers Creating Stop Motion Animation on Tablets. International Journal of Education in Mathematics, Science and Technology, 6(2), 182-199. https://doi.org/10.18404/ijemst.408942

Pakprod, N., \& Wannapiroon, P. (2014). Development of Interactive Instructional Model Using Augmented Reality based on Edutainment to Enhance Emotional Quotient. IJITE, 2(4), 43-50. https://doi.org/10.5121/ijite.2013.2405

Panetta, K. (2017). Gartner Top 10 Strategic Technology Trends for 2018. Retrieved from https://www.gartner.com/smarterwithgartner/gartner-top-10-strategic-technology-trends-for-2018/

Panich, W. (2013). Creating a 21st Century Learning. Bangkok: Siam Commercial Foundation.

Project Management. (2014). Introduction to Gamification. Buckinghamshire.

Rattanawijarn, T., \& Pongsanit, C. (2016). "Merged Reality" become "Reality" in Manufacture industry. Journal of Communication and Management NIDA, 2(3), 97-114.

Srifa, P. (2016). Interactive Learning by Using Augmented Reality Technology: The Development of Electronic Publication Course for Education in Thailand. TOJET, Dubai, UAE.

Suwanapichon, R. (1996). The history of Mahajanaka. Sroitong Publishing.

Tansiri, P. (2010). Augmented Reality. Executive Journal, 30(2), 169-173. Bangkok University.

Techakosit, S., \& Nilsook, P. (2016). The Learning Process of Scientific Imagineering through AR in Order to Enhance STEM Literacy. International Journal of Emerging Technologies in Learning (iJET), 11(7), 57-63. 
https://doi.org/10.3991/ijet.v13i01.7664

Tomorrowtodayglobal. (2018). 16 Skills for 21st Century Education. Retrieved from http://www.tomorrowtodayglobal.com/2016/04/25/16-skills-21st-century-education/

Toon Goggles. (2018). Learn Something New: Types of Animation. Retrieved from http://www.toongoggles.com/article/181646/learn-something-new:-types-of-animation

Unkelos-Shpigel, N., \& Hader, I. (2015). Inviting Everyone to Play: Gamifying Collaborative Requirements Engineering. EmpiRE 2015, Ottawa, ON, Canada (pp. 13-16).

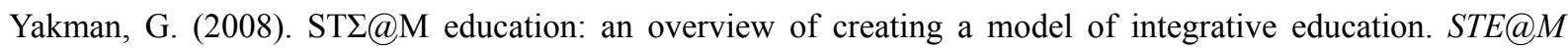
Education Theory, 1-28.

\section{Copyrights}

Copyright for this article is retained by the author(s), with first publication rights granted to the journal.

This is an open-access article distributed under the terms and conditions of the Creative Commons Attribution license (http://creativecommons.org/licenses/by/4.0/). 